\title{
Detailed Analysis of Diffuse Large B Cell Lymphoma Patients: A Single-Center, Retrospective Study
}

\author{
Murat Ozbalak, ${ }^{1}$ M. Cem Ar, ${ }^{1}$ Nukhet Tuzuner, ${ }^{2}$ Ayse Salihoglu, ${ }^{1}$ A. Emre Eskazan, \\ Seniz Ongoren Aydin, ${ }^{1}$ Zafer Baslar, ${ }^{1}$ Teoman Soysal, ${ }^{1}$ Yildiz Aydin, ${ }^{1}$ Anil Barak Dolgun, ${ }^{3}$ \\ Onder Ergonul, ${ }^{4}$ and Burhan Ferhanoglu ${ }^{1}$ \\ ${ }^{1}$ Division of Haematology, Department of Internal Medicine, Istanbul University, Cerrahpasa Medical Faculty, Cerrahpasa Cd., \\ No. 181, Kocamustafapasa-Fatih, 34098 Istanbul, Turkey \\ ${ }^{2}$ Division of Haematopathology, Department of Pathology, Istanbul University, Cerrahpasa Medical Faculty, Istanbul, Turkey \\ ${ }^{3}$ Department of Biostatistics, Hacettepe University Medical Faculty, Ankara, Turkey \\ ${ }^{4}$ Department of Infectious Diseases, Koç University Medical School, Istanbul, Turkey
}

Correspondence should be addressed to Burhan Ferhanoglu; bferhan@superonline.com

Received 5 June 2013; Accepted 9 July 2013

Academic Editors: L. Bordin, A. Bosly, D. Del Principe, K. Oritani, and F. W. Quelle

Copyright (C) 2013 Murat Ozbalak et al. This is an open access article distributed under the Creative Commons Attribution License, which permits unrestricted use, distribution, and reproduction in any medium, provided the original work is properly cited.

\begin{abstract}
The aim of this single-center, retrospective study was to investigate the impact of rituximab, reconsider the validity of International Prognostic Index (IPI), and evaluate the prognostic role of the cell of origin $(\mathrm{CoO})$ in a relatively young cohort. Three hundred twelve diffuse large B cell lymphoma patients (median age: 52) were included. Rituximab significantly improved the 3- and 5-year progression free survival (PFS) $(70 \%$ versus $65 \%$ and $41 \%$ versus $36 \%$, resp.; $P<0.001)$ but led only to a slight, insignificant increase in 3- and 5-year overall survival (OS) ( $71 \%$ versus $77.3 \%$ and $\% 67$ versus $74.5 \%$, resp.; $P=0.264)$. In the young, low risk patient subgroup (aaIPI $=0 \& 1 ; n=129)$, rituximab improved 3- and 5-year PFS and OS rates $(P<0.001$ and $P=0.048$, resp.). The efficacy of rituximab in young high risk patients was comparable to the literature. CoO data were available in 190 patients. The OS at 3 years was $79 \%$ for GC and $64 \%$ for non-GC subgroups $(P=0.014)$. To the best of our knowledge, this is the first study which investigated the impact of R-CHOP in the context of $\mathrm{CoO}$ and IPI in a relatively young cohort. $\mathrm{CoO}$ was not an independent risk factor for prognosis in the multivariate analysis although patients with GC showed a significant survival advantage in the univariate analysis. $\mathrm{CoO}$ was also found to be a significant determinant of response in refractory/relapsed patients. Our results confirm the efficacy of rituximab in low and high risk, young patients outside of a randomized clinical trial setting.
\end{abstract}

\section{Introduction}

Diffuse large B cell lymphoma (DLBCL), being the most common morphological type, constitutes about $40 \%$ of newly diagnosed non-Hodgkin's lymphoma (NHL) cases. It is a heterogeneous disease with variable clinical course and prognostic outcome. Addition of the immunotherapeutic agent rituximab to chemotherapy improved the response rates in NHL [1]. However, despite major progress in the treatment, responses are not durable and the outcome is fatal in almost half of the patients with DLBCL. Therefore, great interest has been shown to develop prognostic scoring systems that would predict the outcome and identify patients with worst prognosis who would benefit from treatment strategies other than the standard regimens.

Until recently, International Prognostic Index (IPI) [2] was almost the only widely used prognostic indicator in DLBCL. However, increasing evidence suggest that IPI fails to predict the prognosis in a considerable portion of patients with DLBCL. Consequently, there is a need for an improved and/or refined prognostic index which would predict the outcome more precisely. In search for such an index, various immunohistochemical markers have been investigated in DLBCL. Gene expression profiling studies identified three prognostically significant groups defined as "germinal center B cell (GCB)," "activated B cell," and "primary mediastinal 
B cell" $[3,4]$. High cost and technical requirements render gene expression studies impractical for routine use in most centers. To overcome this restriction Hans et al. proposed immunohistochemical methods which can differentiate GCB from nongerminal center B cell (NON-GC) DLBCL and efficiently replace gene expression profiling [5].

To detect the behaviour of the disease in young population, there are some clinical trials on the outcome of DLBCL in young cohorts [6]; however the data about real-life young patients are scarce.

The aim of this single-center study was to investigate the impact of rituximab on the outcome of DLBCL in both low and high risk groups, to reconsider the validity of the International Prognostic Index (IPI), and to evaluate the prognostic role of the cell of origin $(\mathrm{CoO})$ ("germinal center $\mathrm{B}$ cell-like (GC)," "activated B cell") in a relatively young cohort of patient outside of a prospective clinical trial setting.

\section{Patients and Methods}

2.1. Patients. All patients $(n=312)$ diagnosed with DLBCL according to the World Health Organization criteria [7] and followed at the Haematology Department of Cerrahpasa Medical Faculty, Istanbul University, from January 2000 to May 2011, were retrospectively included in this analysis. No preset selection criteria were defined for patient inclusion in the study except the pathologically confirmed diagnosis of DLBCL. The patient characteristics are given in Table 1.

2.2. Ethics. The study was approved by the local ethics committee and conducted in accordance with the rules of Good Clinical Practice and Helsinki Declaration.

2.3. Definitions. Patients were staged according to Ann Arbor classification [8]. Complete response (CR), partial response (PR), progression, refractory disease, and relapse were defined according to ECOG criteria [9]. Any tumor mass measuring greater than $5 \mathrm{~cm}$ was accepted as "bulky disease" [10].

2.4. Histopathological Analysis. Histopathological analysis of the lymph node materials was carried out at the Pathology Department of Cerrahpasa, Medical Faculty, by an expert hematopathologist. Identification of $\mathrm{CoO}$ as GC or non-GC was done according to the algorithm proposed by Hans et al. [5].

2.5. Statistical Methods. Statistical analyses were done with STATA/SE version 10.1 for Windows and $\mathrm{R}$ version 2.11.1. All patients, diagnosed with DLBCL before January 2004 $(n=54)$, were treated with CHOP (cyclophosphamide, doxorubicin, vincristine, and prednisolone) regimen. Following the approval of the reimbursement of rituximab in Turkey in December 2003, rituximab added CHOP or CHOP-like regimens became the standard first-line chemotherapy for DLBCL. The treatment cycles were applied every three weeks. In the study the patients were primarily assessed according to their response to the first-line treatment.

\section{Results}

A total of 312 DLBCL patients were retrospectively included. The cohort consisted of relatively young patients with a median age of 52 years. One-third of the patients had high risk characteristics (Table 1). Among the 190 patients analyzed for the $\mathrm{CoO}, 104$ and 86 patients had GC and non-GC types, respectively. In the cohort, there were also 34 patients with $\mathrm{T}$ cell rich $\mathrm{B}$ cell lymphoma (TCRBCL) and 10 primary mediastinal large B-cell lymphomas (PMBCL). Twenty-two percent of patients had primary extranodal disease, most of which were primary gastrointestinal lymphomas (Table 2). High dose chemotherapy and autologous peripheral blood stem cell transplantation were performed in 25 patients at relapse (7 in GC, 6 in non-GC, and 12 in unspecified subgroup).

3.1. Survival Analyses. Survival data were updated as of June 2012. The Kaplan-Meier estimates of 3- and 5-year OS rates for the entire cohort were $76.2 \%$ (\%95 CI: 0.71-0.81) and 73.1\% (\%95 CI: 0.67-0.78), respectively. Median follow-up period was 40 months (range, 1-142). PFS rates at 3 and 5 years were $64.5 \%$ (\%95 CI $0.59-0.70)$ and 59.6\% (\%95 CI $0.53-$ 0.65), respectively. Among patients who relapsed after having achieved $\mathrm{CR}$ with the first-line treatment, the median time to relapse (TTR) was 10 months (range, 1-53). Survival results according to the $\mathrm{CoO}$ are given in Table 3 .

3.2. Comparison according to Treatment. First-line treatment resulted in CR in 248 patients (80\%). PR was achieved in 10 patients (3\%), whereas 1 patient had stable disease (SD) and 52 patients (17\%) had progressive disease. Rituximab added to chemotherapy significantly improved PFS and ameliorated OS by $7 \%$. The patient characteristics of the two treatment groups are detailed in Table 5 and the impact of rituximab on the survival rates is given in Table 3 .

3.3. Comparison according to $\mathrm{CoO}$. The $\mathrm{CoO}$ was not an independent prognostic factor in our cohort of patients. The analysis of 190 patients with defined $\mathrm{CoO}$ resulted in similar patient characteristics apart from the LDH levels (Table 4).

The OS rates at 3 and 5 years were both 79\% (95\% CI: $0.69-0.86)$ for GC and 64\% (95\% CI: $0.53-0.74)$ for nonGC subgroups $(P=0.014$ median follow-up 38 versus 31 months, Table 3). We found lower mortality rates in the GC group $(P=0.023)$. GC type favoured a survival advantage and lower mortality rate even in patients treated with $\mathrm{CHOP}$ $(P=0.004)$. Three- and 5-year OS rates in patients who received R-CHOP were $81 \%$ (95\% CI: $0.70-0.88$ ) for GC and 63\% (95\% CI: 0.51-0.73) for non-GC group (median followup 38 versus 31 months, $P=0.006$, Figure 1 ). On the other hand, the progression rates were similar in both groups $(P=$ 0.181 , Table 3).

Response to the first-line treatment in the GC group was significantly better than the non-GC group; the CR rates were $83 \%$ and $74 \%$, respectively. Refractoriness to the first-line treatment was significantly higher in non-GC group $(P=$ $0.012)$. 
TABLE 1: Patient characteristics.

\begin{tabular}{|c|c|c|c|c|c|}
\hline & $\begin{array}{c}\text { All patients } \\
N=312\end{array}$ & $\begin{array}{l}\text { Loss of the follow-up } \\
\qquad N=30\end{array}$ & $\begin{array}{c}\text { Survivors } \\
N=205\end{array}$ & $\begin{array}{c}\text { Dead } \\
N=77\end{array}$ & $P$ value* \\
\hline Female & 143 & 17 & 96 & 30 & 0.123 \\
\hline Male & 169 & 13 & 110 & 46 & \\
\hline Mean/median age (range) & $51.3 / 52(17-83)$ & $54.9 / 55$ & $48.3 / 47.5$ & $58 / 60(32-83)$ & 0.104 \\
\hline \multicolumn{6}{|l|}{ Subgroup } \\
\hline GCB & 104 & 7 & 77 & 20 & \\
\hline Non-GC & 86 & 7 & 49 & 30 & 0.023 \\
\hline Unknown & 122 & 16 & 79 & 27 & \\
\hline \multicolumn{6}{|l|}{ Treatment regimen } \\
\hline CHOP based & 54 & 10 & 25 & 19 & \\
\hline R-CHOP based & 258 & 20 & 180 & 58 & 0.042 \\
\hline \multicolumn{6}{|l|}{ Stage } \\
\hline 1 & 75 & 10 & 58 & 7 & \\
\hline 2 & 66 & 4 & 50 & 12 & \\
\hline 3 & 86 & 9 & 49 & 28 & \\
\hline 4 & 85 & 7 & 48 & 30 & $<0.001$ \\
\hline \multicolumn{6}{|l|}{ Age } \\
\hline$<60$ & 208 & 19 & 151 & 38 & \\
\hline$\geq 60$ & 104 & 11 & 54 & 39 & $<0.001$ \\
\hline \multicolumn{6}{|l|}{$\mathrm{LDH}$} \\
\hline Normal & 145 & 17 & 108 & 20 & \\
\hline High & 162 & 13 & 93 & 56 & $<0.001$ \\
\hline \multicolumn{6}{|l|}{ Extranodal } \\
\hline$<2$ & 220 & 24 & 152 & 44 & \\
\hline$\geq 2$ & 92 & 6 & 53 & 33 & 0.002 \\
\hline \multicolumn{6}{|l|}{ Performance $^{\mu}$} \\
\hline$\geq 70$ & 263 & 27 & 183 & 53 & \\
\hline$<70$ & 49 & 3 & 22 & 24 & $<0.001$ \\
\hline \multicolumn{6}{|l|}{ BMI } \\
\hline No & 252 & 22 & 173 & 57 & \\
\hline Yes & 57 & 6 & 32 & 19 & 0.090 \\
\hline \multicolumn{6}{|l|}{ Bulky mass $(>5 \mathrm{~cm})$} \\
\hline No & 179 & 20 & 116 & 43 & \\
\hline Yes & 129 & 9 & 87 & 33 & 0.754 \\
\hline \multicolumn{6}{|l|}{ IPI } \\
\hline $0-1$ & 139 & 18 & 106 & 15 & \\
\hline 2 & 68 & 5 & 48 & 15 & \\
\hline 3 & 59 & 5 & 32 & 22 & \\
\hline $4-5$ & 43 & 2 & 18 & 23 & $<0.001$ \\
\hline \multicolumn{6}{|l|}{ aaIPI } \\
\hline 0 & 67 & 7 & 56 & 4 & \\
\hline 1 & 62 & 5 & 46 & 11 & \\
\hline 2 & 53 & 4 & 37 & 12 & \\
\hline 3 & 18 & 2 & 8 & 8 & 0.002 \\
\hline \multicolumn{6}{|l|}{ Primary extranodal } \\
\hline No & 243 & 22 & 153 & 68 & \\
\hline Yes & 69 & 8 & 53 & 8 & 0.005 \\
\hline
\end{tabular}

GC: germinal center B cell.

Non-GC: nongerminal center B Cell.

$\mathrm{LDH}$ : lactate dehydrogenase.

BMI: bone marrow involvement at initial diagnosis.

${ }^{*}$ Comparison between surviving and dead patients.

${ }^{\mu}$ Karnofsky performance scale. 
TABLE 2: Primary extranodal lymphomas.

\begin{tabular}{lc}
\hline Stomach & 20 \\
Ileum & 4 \\
Rectosigmoid junction & 1 \\
Tongue & 1 \\
Submandibular salivary gland & 1 \\
Liver & 2 \\
Spleen & 1 \\
Nasopharynx & 2 \\
Lung & 2 \\
Larynx & 1 \\
Tonsil & 9 \\
Thyroid & 5 \\
Musculoskeletal system & 12 \\
Leg & 1 \\
Ovary & 2 \\
Breast & 1 \\
Spinal cord & 1 \\
Paranasal sinus & 1 \\
Orbita & 2 \\
\hline
\end{tabular}

Among the 95 patients, who had primary refractory or relapse disease in our cohort, $\mathrm{CoO}$ results were only available for 67 patients. In this subgroup, $\mathrm{CoO}$ was the only significant determinant of progression $(P=0.003)$.

3.4. Parameters Affecting the Prognosis. Univariate analysis highlighted advanced age, advanced stage of the disease, elevated lactate dehydrogenase $(\mathrm{LDH})$ level, low performance status, and non-GC type as prognostic determinants (all $P<$ $0.05)$. Extranodal involvement ( $>1$ site), however, was not associated with clinical outcome $(P=0.276)$. This is in line with the original report [2] and can similarly be explained by the low median age (52 years) of our cohort. The OS and PFS rates according to IPI scores are shown in Figure 2. Among the 52 patients with primary refractory disease, all IPI parameters were found to be statistically insignificant (all $P>0.05)$ in the univariate analysis.

We also did a subanalysis for prognostic outcome in the 190 patients with defined $\mathrm{CoO}$. Advanced age, advanced stage, increased LDH levels, and low performance status significantly indicated a poor prognosis, whereas involvement of more than one extranodal site, diagnosis of primary extranodal lymphoma, and $\mathrm{CoO}$ were not associated with the prognosis (Table 6). Other parameters tested for prognostic outcome [11-16] (presence of B symptoms, liver involvement, spleen involvement, bone marrow involvement, bulky mass $>5 \mathrm{~cm}$, need for radiotherapy, extranodal involvement $\geq 3$ sites, neutrophil/lymphocyte ratio $>3.5$, and absolute lymphocyte count $<800 / \mu \mathrm{L}$ ) were insignificant. Initial thrombocyte level was available in 236 patients and a value less than $150 \times 10^{9} / \mathrm{L}$ [17] was associated with increases in mortality $(P=0.013)$, bone marrow involvement $(P=0.009)$, splenic involvement $(P=0.016)$, and $\mathrm{LDH}$ level $(P=0.040)$ in univariate analysis, but it had no effect on prognosis in the multivariate analysis.

Of the 248 patients who initially achieved CR, 43 relapsed (median TTR: 10 months, range: 1-53). Involvement at more than one extranodal site $(P=0.001)$, advanced stage of the disease $(P<0.001)$, and elevated LDH level $(P=0.004)$ were associated with relapse in univariate analysis. In multivariate analysis, however, no risk factor was identified (all $P>0.05$ ).

\section{Discussion}

Rituximab has been shown to be efficacious in the elderly as well as in the young low risk patients with DLBCL. Randomized studies on the effect of rituximab in newly diagnosed poor risk relatively young patients are scarce. These patients have also not been adequately represented in registry based studies. Consequently there is no consensus on how to treat this subgroup of patients. Young high risk patients have mainly been investigated in the setting of dose dense regimens and first-line high dose treatment with autologous stem cell support [18-20]. None of the studies showed a clear benefit in terms of overall survival. With the exception of MInT trial [6] there are no major rituximab studies on newly diagnosed young ( $<60$ years) patients. Okamoto et al. newly published their retrospective data indicating improvement in the PFS of the patients older than 60 years in rituximab era [21]. Sehn et al. reported their results in rituximab era, comparing it with pre-rituximab era; however the median age of this population registry base study was 64 [22]. To the best of our knowledge, this study is one of the very few studies that evaluate the impact of rituximab on newly diagnosed DLBCL in a relatively young cohort outside of a clinical trial setting.

Our cohort differed from the aforementioned rituximab studies in many aspects. First of all, it included a relatively young group of patients with a median age of 52 years. Furthermore, it included patients outside of a clinical trial protocol, that is, without any selection criteria. One-third of the patients had high risk disease according to IPI score.

Although we found similar response rates with R-CHOP and CHOP regimens, the 3- and 5-year PFS estimates in the $\mathrm{R}-\mathrm{CHOP}$ and $\mathrm{CHOP}$ groups differed significantly. Our cohort was relatively small to predict overall survival difference. In our hands, rituximab significantly improved the PFS but the increase in OS was around $10 \%$.

Gene expression profiling has been reported to be an IPI independent prognostic marker [3]. Hans et al. [5] were the first to differentiate some surrogate groups by tissue IHC instead of gene expression profiling and reported a 5year OS rate of $76 \%$ for GC and 34\% for non-GC types. These results were confirmed by several other studies [2326]. Thieblemont et al. demonstrated the influence of $\mathrm{CoO}$ in relapsed/refractory DLBCL patents [27]. Others, however, could not show the prognostic significance of $\mathrm{CoO}[28,29]$.

In our single-centre retrospective analysis, $\mathrm{CoO}$ studies were done in 190 of the 312 patients (Table 4). LDH levels and mortality rates were significantly elevated in non-GC group, which might be explained by the aggressive behavior of this type $(P=0.023)$. The 5 -year OS rates of the GC and non-GC 
TABLE 3: OS and PFS rates in different subgroups according to $\mathrm{CoO}$ and treatment modalities.

\begin{tabular}{lccccc}
\hline & $\begin{array}{c}\text { Median follow-up } \\
\text { period }\end{array}$ & 3 years (95\% CI) & 5 years (95\% CI) & 3 years (95\% CI) & 5 years (95\% CI) \\
\hline GC Subgroup $(n=104)$ & 38 months & $0.79(0.69-0.86)$ & $0.79(0.69-0.86)$ & $0.70(0.60-0.78)$ & $0.61(0.48-0.71)$ \\
Non-GC subgroup $(n=86)$ & 31 months & $0.64(0.53-0.74)$ & $0.64(0.51-0.72)$ & $0.61(0.49-0.70)$ & $0.61(0.49-0.70)$ \\
\hline Significance level & & $P=0.014$ & $P=0.573$ & $0.41(0.27-0.54)$ \\
\hline R-CHOP Group $(n=258)$ & 37 months & $0.77(0.71-0.82)$ & $0.74(0.68-0.80)$ & $0.70(0.64-0.75)$ & $0.36(0.23-0.49)$ \\
CHOP Group $(n=54)$ & 60 months & $0.71(0.57-0.82)$ & $0.67(0.52-0.82)$ & $0.65(0.58-0.71)$ & $P<0.001$ \\
\hline \multicolumn{2}{c}{ Significance level } & & $P=0.264$ & & $P$ \\
\hline
\end{tabular}

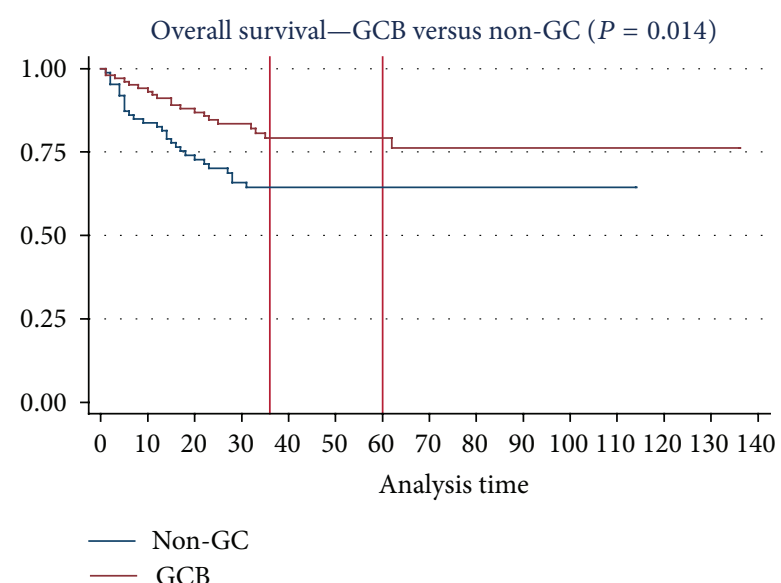

(a)

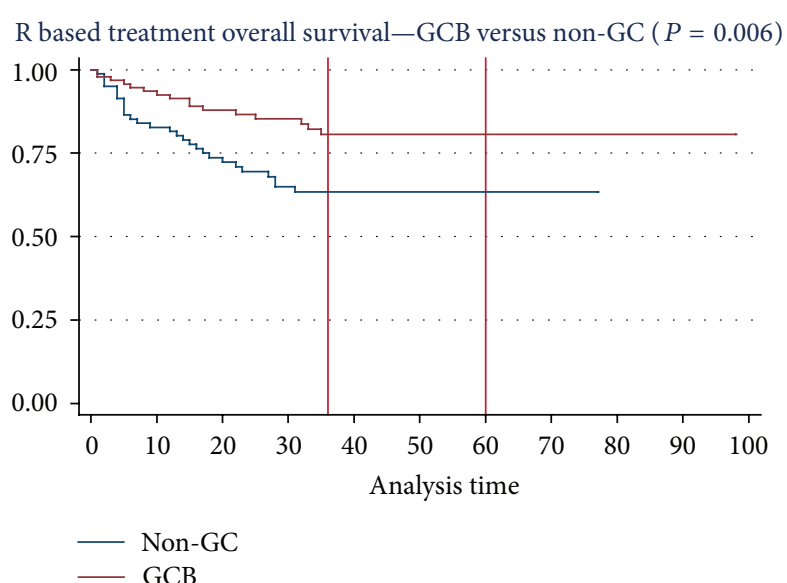

(b)

FIGURE 1: Kaplan Meier survival estimates-GC versus non-GC.
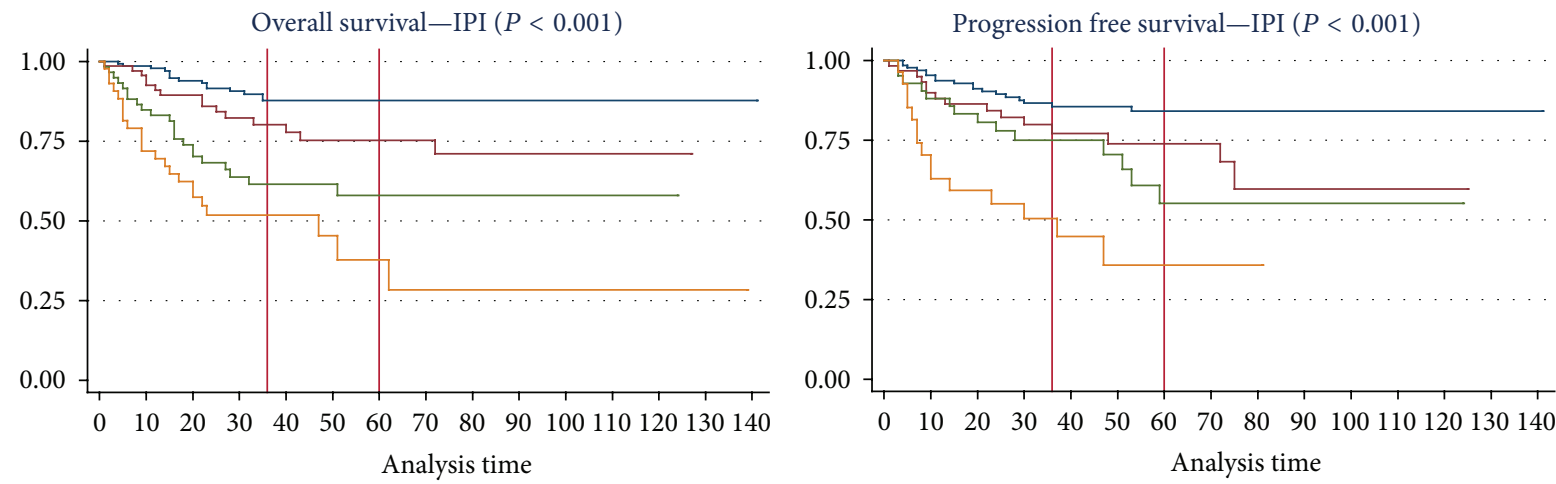

\begin{tabular}{|c|c|c|}
\hline \multicolumn{2}{|c|}{$\begin{array}{l}\mathrm{IPI}=0-1 \\
\mathrm{IPI}=3\end{array}$} & $\begin{array}{l}\mathrm{IPI}=2 \\
\mathrm{IPI}=4-5\end{array}$ \\
\hline \multicolumn{3}{|c|}{ Overall survival } \\
\hline & 3-year (95\% CI) & 5-year $(95 \% \mathrm{CI})$ \\
\hline $0-1$ & $0.88(0.80-0.93)$ & $0.88(0.80-0.93)$ \\
\hline 2 & $0.80(0.67-0.88)$ & $0.75(0.61-0.85)$ \\
\hline 3 & $0.61(0.47-0.73)$ & $0.58(0.43-0.70)$ \\
\hline 4-5 & $0.52(0.35-0.66)$ & $0.37(0.18-0.57)$ \\
\hline
\end{tabular}

(a)

IPI $=0-1 \quad$ IPI $=2$
IPI $=3$
\begin{tabular}{|c|c|c|}
\hline \multicolumn{3}{|c|}{ Progression free survival } \\
\hline & 3 -year $(95 \% \mathrm{CI})$ & 5 -year $(95 \% \mathrm{CI})$ \\
\hline $0-1$ & $0.86(0.71-0.85)$ & $0.84(0.69-0.84)$ \\
\hline 2 & $0.77(0.54-0.78)$ & $0.74(0.51-0.76)$ \\
\hline 3 & $0.75(0.39-0.65)$ & $0.55(0.24-0.54)$ \\
\hline $4-5$ & $0.55(0.15-0.43)$ & $0.36(0.09-0.38)$ \\
\hline
\end{tabular}

(b)

Figure 2: Kaplan Meier survival estimates according to the International Prognostic Index. 
TABLE 4: Comparison according to cell of origin.

\begin{tabular}{|c|c|c|c|}
\hline & $\begin{array}{c}\mathrm{GC} \\
N=104(\%)\end{array}$ & $\begin{array}{c}\text { Non-GC } \\
N=86(\%)\end{array}$ & $P$ value \\
\hline Female & $42(40)$ & $43(50)$ & \\
\hline Male & $62(60)$ & $43(50)$ & 0.330 \\
\hline Mean age & 51 & 54.5 & \\
\hline Median age (range) & $51(20-81)$ & $55(26-80)$ & 0.441 \\
\hline \multicolumn{4}{|l|}{ Treatment strategy } \\
\hline $\mathrm{CHOP}$ & $9(9)$ & $5(6)$ & \\
\hline R-CHOP & $95(91)$ & $81(94)$ & 0.456 \\
\hline \multicolumn{4}{|l|}{ Radiotherapy } \\
\hline Yes & $25(24)$ & $14(16)$ & \\
\hline No & $79(76)$ & $72(84)$ & 0.187 \\
\hline \multicolumn{4}{|l|}{ Stage } \\
\hline 1 & $28(27)$ & $20(23)$ & \\
\hline 2 & $28(27)$ & $13(15)$ & \\
\hline 3 & $27(26)$ & $31(36)$ & \\
\hline 4 & $21(20)$ & $22(26)$ & 0.141 \\
\hline \multicolumn{4}{|l|}{ Age } \\
\hline$<60$ & $69(66)$ & $52(60)$ & \\
\hline$\geq 60$ & $35(34)$ & $34(40)$ & 0.401 \\
\hline \multicolumn{4}{|l|}{$\mathrm{LDH}$} \\
\hline Normal & $60(58)$ & $37(43)$ & \\
\hline High & $44(42)$ & $49(57)$ & 0.044 \\
\hline \multicolumn{4}{|l|}{ Extranodal } \\
\hline$<2$ & $78(75)$ & $62(72)$ & \\
\hline$\geq 2$ & $26(25)$ & $24(28)$ & 0.651 \\
\hline \multicolumn{4}{|l|}{ Performance } \\
\hline$\geq 70$ & $92(88)$ & $74(86)$ & \\
\hline$<70$ & $12(12)$ & $12(14)$ & 0.618 \\
\hline \multicolumn{4}{|l|}{ IPI } \\
\hline $0-1$ & $55(53)$ & $34(40)$ & \\
\hline 2 & $24(23)$ & $20(23)$ & \\
\hline 3 & $14(13)$ & $16(18.5)$ & \\
\hline $4-5$ & $11(11)$ & $16(18.5)$ & 0.194 \\
\hline
\end{tabular}

groups were $76 \%$ and $64 \%(P=0.014)$, respectively, which was in accordance with the current literature. The CR rates were $83 \%$ and $74 \%$ in the GC and the non-GC groups, respectively. Twelve percent of the patients in the GC and $24 \%$ in the non-GC group were refractory to the first-line treatment $(P=0.012)$. Moreover, the CoO was the only significant prognostic factor in the multivariate analysis of progressed patients $(P=0.003)$, with the non-GC being worse.

Recently, several articles questioned the validity of IPI score in DLBCL in the context of rituximab [30]. However, we could demonstrate a clear stratification of OS and PFS rates in our cohort according to IPI score (Figure 2). Having extranodal involvement ( $>1$ site) had no prognostic significance.
TABLE 5: Comparison according to the treatment.

\begin{tabular}{|c|c|c|c|}
\hline & $\begin{array}{c}\text { CHOP based } \\
N=54(\%)\end{array}$ & $\begin{array}{c}\text { R-CHOP } \\
\text { based } \\
N=258(\%)\end{array}$ & $P$ value \\
\hline Female & $24(44)$ & $119(46)$ & \\
\hline Male & $30(56)$ & $139(54)$ & 0.822 \\
\hline Mean age & 47.8 & 52 & \\
\hline Median age (range) & $46(17-80)$ & $53(19-81)$ & 0.183 \\
\hline \multicolumn{4}{|l|}{ Cell of origin } \\
\hline GC & $9(36)$ & $95(54)$ & \\
\hline Non-GC & $5(64)$ & $81(46)$ & 0.456 \\
\hline \multicolumn{4}{|l|}{ Radiotherapy } \\
\hline Yes & $13(24)$ & $57(22)$ & \\
\hline No & $41(56)$ & $201(78)$ & 0.751 \\
\hline \multicolumn{4}{|l|}{ Stage } \\
\hline 1 & $12(22)$ & $63(24)$ & \\
\hline 2 & $10(19)$ & $56(22)$ & \\
\hline 3 & $15(28)$ & $71(28)$ & \\
\hline 4 & $17(31)$ & $68(26)$ & 0.865 \\
\hline \multicolumn{4}{|l|}{ Age } \\
\hline$<60$ & $39(72)$ & $169(66)$ & \\
\hline$\geq 60$ & $15(28)$ & $89(34)$ & 0.341 \\
\hline \multicolumn{4}{|l|}{$\mathrm{LDH}$} \\
\hline Normal & $24(48)$ & $121(47)$ & \\
\hline High & $26(52)$ & $136(53)$ & 0.905 \\
\hline \multicolumn{4}{|l|}{ Extranodal } \\
\hline$<2$ & $38(70)$ & $182(71)$ & \\
\hline$\geq 2$ & $16(30)$ & $76(29)$ & 0.980 \\
\hline \multicolumn{4}{|l|}{ Performance } \\
\hline$\geq 70$ & $42(78)$ & $231(86)$ & \\
\hline$<70$ & $12(22)$ & $37(14)$ & 0.148 \\
\hline \multicolumn{4}{|l|}{ IPI } \\
\hline $0-1$ & $24(46)$ & $15(45)$ & \\
\hline 2 & $12(24)$ & $56(22)$ & \\
\hline 3 & $9(18)$ & $50(19)$ & \\
\hline $4-5$ & $6(12)$ & $37(14)$ & 0.942 \\
\hline
\end{tabular}

Extranodal involvement ( $>1$ site) was reported not to retain independent prognostic significance in patients younger than 60 years old in the original IPI study [2]. The lower median age (52 years old) in our cohort might explain this. IPI worked very well in our cohort of patients including those treated with rituximab. In opposition to the suggestion of Sehn et al. [31], we do not think that there is a need for the restratification of the IPI. But perhaps, the impact of the CoO on the IPIpredicted outcomes might be investigated in larger patient groups to see whether this helps to refine the definition of the patients with the worst prognosis.

The survival rates among the young, low risk patients (aaIPI scores 0 and 1) in our cohort were lower when 
TABLE 6: Multivariate analysis of prognostic factors significant in univariate analysis results.

\begin{tabular}{lccr}
\hline & Hazard ratio & $P$ value & $95 \%$ confidence interval \\
\hline Advanced age & $\mathbf{2 . 5 2}$ & $\mathbf{0 . 0 0 2}$ & $\mathbf{1 . 4 0 - 4 . 5 3}$ \\
Advanced stage & $\mathbf{2 . 3 7}$ & $\mathbf{0 . 0 3 8}$ & $\mathbf{1 . 0 5}-\mathbf{5 . 3 8}$ \\
Low performance & $\mathbf{2 . 4 5}$ & $\mathbf{0 . 0 1 1}$ & $\mathbf{1 . 2 3}-\mathbf{4 . 8 7}$ \\
High LDH & $\mathbf{2 . 4 8}$ & $\mathbf{0 . 0 1 3}$ & $\mathbf{1 . 2 0 - 5 . 0 9}$ \\
Extranodal $\geq 2$ sites & 0.68 & 0.276 & $0.34-1.36$ \\
Non-GC subgroup & 1.62 & 0.103 & $0.91-2.89$ \\
Primary extranodal disease & 1.11 & 0.824 & $0.44-2.83$ \\
\hline
\end{tabular}

compared to the MInT trial [6], but they differed significantly between treatment groups, being better in the R-CHOP group. Three- and 5-year OS rates were 90\% for R-CHOP $(n=107)$ and $72 \%$ for CHOP $(n=22)$ groups $(P=$ 0.048 ). Similarly, 3-year and 5-year PFS rates were 93\% versus $53 \%$ and $91 \%$ versus $53 \%$ for R-CHOP and CHOP groups, respectively $(P<0.001)$.

To test the efficacy of rituximab in the young poor risk population we performed a subgroup analysis on the 71 young patients (age $\leq 60$ years) with aaIPI scores of $2-3$ in the cohort. $\mathrm{R}-\mathrm{CHOP}$ versus $\mathrm{CHOP}$ comparison was not done since only 13 patients received $\mathrm{CHOP}$ based treatment. In the R-CHOP group, the 3 - and 5-year OS were both $71 \%$, and 3 and 5year PFS rates were $75 \%$ and $64 \%$. To compare our results with the literature, we analyzed the 2-year survival rates of R-CHOP group. Forty-five of the 71 young patients had an aaIPI score of 2 . Their 2 -year OS and PFS rates were $83 \%$ and $79 \%$, respectively. Thirteen patients with an aaIPI score of 3 had 2 -year OS and PFS rates of 59\% and 75\%, respectively. Vitolo et al. reported a 2-year PFS rate of $\% 72$ and an OS rate of $83 \%$ with high dose treatment in a similar population [32]. In another study, 2-year PFS rates in high-intermediate and high IPI groups were $66 \%$ and $75 \%$, respectively, with corresponding OS rates of $70 \%$ and $82 \%$ [33].

Our single-center retrospective cohort study has some limitations and its results should therefore be cautiously interpreted. First of all, treatment groups were not stratified according to treatment dose intensity, Second, side effect analysis was not performed in the treatment groups. Third, the number of patients who received CHOP $(n=54)$ was small. This might be the underlying reason for the statistically insignificant improvement of OS.

In conclusion, our results demonstrated that IPI still works and is valid in rituximab era outside of a clinical trial setting, in a cohort consisting of relatively young DLBCL patients. To our knowledge, this is the first study which investigated the impact of R-CHOP in the context of $\mathrm{CoO}$ and IPI in a relatively young cohort of patients. In this cohort, $\mathrm{CoO}$ was not an independent risk factor for prognosis in the multivariate analysis although patients with GC showed a significant survival advantage in the univariate analysis. $\mathrm{CoO}$ was an important and significant determinant of the response in refractory/relapsed patients. The survival rates among the young, low risk patients were lower when compared to the MInT trial, but they significantly differed between treatment groups, being better in the R-CHOP group. Rituximab was also effective in poor risk, young patients with intermediate/high risk factors.

\section{Authors' Contribution}

Burhan Ferhanoglu, M. Cem Ar, and Murat Ozbalak designed the study. Murat Ozbalak collected the data. Murat Ozbalak, M. Cem Ar, Nukhet Tuzuner, and Burhan Ferhanoglu analyzed the data, interpreted the results, and wrote the paper. Anil Barak Dolgun, Onder Ergonul, Murat Ozbalak, M. Cem Ar, and Burhan Ferhanoglu performed statistical analysis. Ayse Salihoglu, A. Emre Eskazan, Seniz Ongoren Aydin, Zafer Baslar, Teoman Soysal, and Yildiz Aydin performed research and reviewed the paper.

\section{Conflict of Interests}

The authors have no conflict of interests.

\section{Acknowledgments}

This study was supported by Istanbul University Research Fund contract no. 404/03062005. The authors thank Professor Christian Gisselbrecht for the time he generously spent in reviewing this paper and appreciate the constructive criticism. They also thank Dr. Serap IBISOGLU, Dr. Ece TURKYILMAZ UYAR, and Dr. Erdem CAGLAR for their help while screening the patient files.

\section{References}

[1] B. Coiffier, E. Lepage, J. Brière et al., "Chop chemotherapy plus rituximab compared with chop alone in elderly patients with diffuse large-B-cell lymphoma," New England Journal of Medicine, vol. 346, no. 4, pp. 235-242, 2002.

[2] M. A. Shipp, D. P. Harrington, J. R. Andersen et al., "A predictive model for aggressive non-Hodgkin's lymphoma," New England Journal of Medicine, vol. 329, no. 14, pp. 987-994, 1993.

[3] A. A. Alizadeh, M. B. Elsen, R. E. Davis et al., "Distinct types of diffuse large B-cell lymphoma identified by gene expression profiling," Nature, vol. 403, no. 6769, pp. 503-511, 2000.

[4] A. Rosenwald, G. Wright, W. C. Chan et al., "The use of molecular profiling to predict survival after chemotherapy for diffuse large-B-cell lymphoma," New England Journal of Medicine, vol. 346, no. 25, pp. 1937-1947, 2002. 
[5] C. P. Hans, D. D. Weisenburger, T. C. Greiner et al., "Confirmation of the molecular classification of diffuse large B-cell lymphoma by immunohistochemistry using a tissue microarray," Blood, vol. 103, no. 1, pp. 275-282, 2004.

[6] M. Pfreundschuh, L. Trümper, A. Österborg et al., "CHOP-like chemotherapy plus rituximab versus CHOP-like chemotherapy alone in young patients with good-prognosis diffuse large-Bcell lymphoma: a randomised controlled trial by the MabThera International Trial (MInT) Group," Lancet Oncology, vol. 7, no. 5, pp. 379-391, 2006.

[7] S. H. Swerdlow, E. Campo, N. L. Harris et al., Who Classification of Tumours of Haematopoietic and Lymphoid Tissues, IARC Press, Lyon, France, 2008.

[8] T. A. Lister, D. Crowther, S. B. Sutcliffe et al., "Report of a committee convened to discuss the evaluation and staging of patients with Hodgkin's disease: cotswolds meeting," Journal of Clinical Oncology, vol. 7, no. 11, pp. 1630-1636, 1989.

[9] M. M. Oken, R. H. Creech, and T. E. Davis, "Toxicology and response criteria of the Eastern Cooperative Oncology Group," American Journal of Clinical Oncology, vol. 5, no. 6, pp. 649-655, 1982.

[10] M. Pfreundschuh, A. D. Ho, E. Cavallin-Stahl et al., "Prognostic significance of maximum tumour (bulk) diameter in young patients with good-prognosis diffuse large-B-cell lymphoma treated with CHOP-like chemotherapy with or without rituximab: an exploratory analysis of the MabThera International Trial Group (MInT) study," The Lancet Oncology, vol. 9, no. 5, pp. 435-444, 2008.

[11] N. Mounier, J. Briere, C. Gisselbrecht et al., "Rituximab plus CHOP (R-CHOP) overcomes bcl-2-associated resistance to chemotherapy in elderly patients with diffuse large B-cell lymphoma (DLBCL)," Blood, vol. 101, no. 11, pp. 4279-4284, 2003.

[12] N. Mounier, J. Briere, C. Gisselbrecht, F. Reyes, P. Gaulard, and B. Coiffier, "Estimating the impact of rituximab on bcl-2associated resistance to CHOP in elderly patients with diffuse large B-cell lymphoma," Haematologica, vol. 91, no. 5, pp. 715716, 2006

[13] C. Yoo, S. Kim, B. S. Sohn et al., "Modified number of extranodal involved sites as a prognosticator in R-CHOP-treated patients with disseminated diffuse large B-cell lymphoma," Korean Journal of Internal Medicine, vol. 25, no. 3, pp. 301-308, 2010.

[14] L. F. Porrata, K. Ristow, T. Habermann, D. J. Inwards, I. N. Micallef, and S. N. Markovic, "Predicting survival for diffuse large B-cell lymphoma patients using baseline neutrophil/lymphocyte ratio," American Journal of Hematology, vol. 85, no. 11, pp. 896-899, 2010.

[15] M. C. Cox, I. Nofroni, L. Ruco et al., "Low absolute lymphocyte count is a poor prognostic factor in diffuse-large-B-celllymphoma," Leukemia and Lymphoma, vol. 49, no. 9, pp. 17451751, 2008.

[16] A. Bari, L. Marcheselli, S. Sacchi et al., "Prognostic models for diffuse large B-cell lymphoma in the rituximab era: a neverending story," Annals of Oncology, vol. 21, no. 7, pp. 1486-1491, 2009.

[17] L. Chen, S. Lin, and M. Yu, "Prognostic value of platelet count in diffuse large B-cell lymphoma," Clinical Lymphoma, Myeloma and Leukemia, vol. 12, no. 1, pp. 32-37, 2012.

[18] C. Tarella, M. Zanni, M. Magni et al., "Rituximab improves the efficacy of high-dose chemotherapy with autograft for highrisk follicular and diffuse large B-cell lymphoma: a multicenter
Gruppo Italiano Terapie Innnovative nei Linfomi survey," Journal of Clinical Oncology, vol. 26, no. 19, pp. 3166-3175, 2008.

[19] U. Vitolo, A. Chiappella, E. Angelucci et al., "Dose-dense and high-dose chemotherapy plus rituximab with autologous stem cell transplantation for primary treatment of diffuse large B-cell lymphoma with a poor prognosis: a phase II multicenter study," Haematologica, vol. 94, no. 9, pp. 1250-1258, 2009.

[20] B. Glass, M. Ziepert, M. Reiser et al., "High-dose therapy followed by autologous stem-cell transplantation with and without rituximab for primary treatment of high-risk diffuse large B-cell lymphoma," Annals of Oncology, vol. 21, no. 11, pp. 2255-2261, 2010.

[21] A. Okamoto, M. Yanada, Y. Inaguma et al., "Differences in outcome for consecutive patients with diffuse large b-cell lymphoma before and after the advent of rituximab: a singlecenter experience," Hematology, vol. 18, pp. 74-80, 2013.

[22] L. H. Sehn, J. Donaldson, M. Chhanabhai et al., "Introduction of combined CHOP plus rituximab therapy dramatically improved outcome of diffuse large B-cell lymphoma in British Columbia," Journal of Clinical Oncology, vol. 23, no. 22, pp. 5027-5033, 2005.

[23] C. Chang, S. McClintock, R. P. Cleveland et al., "Immunohistochemical expression patterns of germinal center and activation B-cell markers correlate with prognosis in diffuse large B-cell lymphoma," American Journal of Surgical Pathology, vol. 28, no. 4, pp. 464-470, 2004.

[24] R. Seki, K. Ohshima, T. Fujisaki et al., "Prognostic impact of immunohistochemical biomarkers in diffuse large B-cell lymphoma in the rituximab era," Cancer Science, vol. 100, no. 10, pp. 1842-1847, 2009.

[25] Y. Liu, F. Xu, H. Zhuang et al., "Clinicopathologic significance of immunophenotypic profiles related to germinal center and activation $\mathrm{B}$-cell differentiation in diffuse large B-cell lymphoma from Chinese patients," Human Pathology, vol. 39, no. 6, pp. 875-884, 2008.

[26] I. Alacacioglu, M. A. Ozcan, S. Ozkal et al., "Prognostic significance of immunohistochemical classification of diffuse large B-cell lymphoma," Hematology, vol. 14, no. 2, pp. 84-89, 2009.

[27] C. Thieblemont, J. Briere, N. Mounier et al., "The germinal center/activated B-cell subclassification has a prognostic impact for response to salvage therapy in relapsed/refractory diffuse large B-cell lymphoma: a bio-CORAL study," Journal of Clinical Oncology, vol. 29, no. 31, pp. 4079-4087, 2011.

[28] H. Veelken, S. Vik Dannheim, J. Schulte Moenting, U. M. Martens, J. Finke, and A. Schmitt-Graeff, "Immunophenotype as prognostic factor for diffuse large B-cell lymphoma in patients undergoing clinical risk-adapted therapy," Annals of Oncology, vol. 18, no. 5, pp. 931-939, 2007.

[29] N. Rayman, K. H. Lam, B. Van Der Holt et al., "Prognostic relevance of immunohistochemical subclassification of diffuse large B-cell lymphoma in two prospective phase III clinical trials," Clinical Lymphoma, Myeloma and Leukemia, vol. 11, no. 1, pp. 23-32, 2011.

[30] L. Ngo, S. W. Hee, L. C. Lim et al., "Prognostic factors in patients with diffuse large B cell lymphoma: before and after the introduction of rituximab," Leukemia and Lymphoma, vol. 49, no. 3, pp. 462-469, 2008.

[31] L. H. Sehn, B. Berry, M. Chhanabhai et al., "The revised International Prognostic Index (R-IPI) is a better predictor of 
outcome than the standard IPI for patients with diffuse large Bcell lymphoma treated with R-CHOP," Blood, vol. 109, no. 5, pp. 1857-1861, 2007.

[32] U. Vitolo, A. Chiappella, E. Brusamolino et al., ICML Annual Meeting, Annals of Oncology, Lugano, Switzerland, 2011.

[33] P. Stiff, J. Unger, J. Cook et al., "Randomized phase iii u.S./canadian intergroup trial (swog s9704) comparing chop $\pm r$ for eight cycles to chop $\pm r$ for six cycles followed by autotransplant for patients with high-intermediate (h-int) or high ipi grade diffuse aggressive non-hodgkin lymphoma (nhl)," in Proceedings of the ASCO Annual Meeting, p. 29, Journal of Clinical Oncology, Chicago, Ill, USA, 2011. 


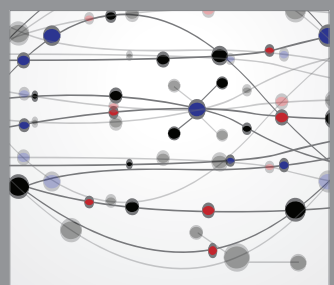

The Scientific World Journal
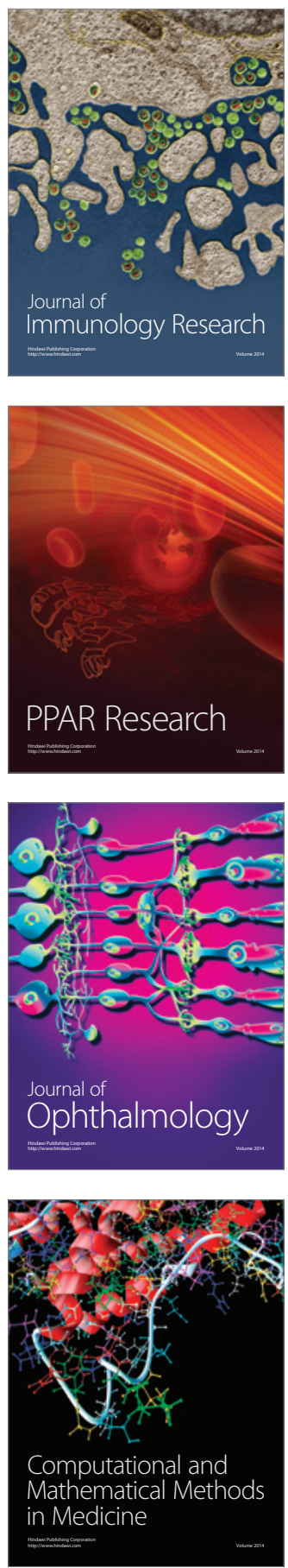

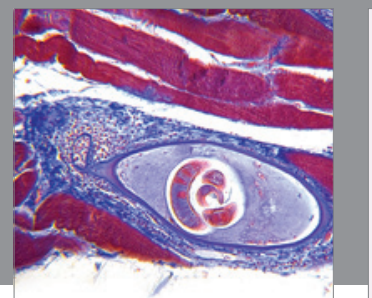

Gastroenterology

Research and Practice
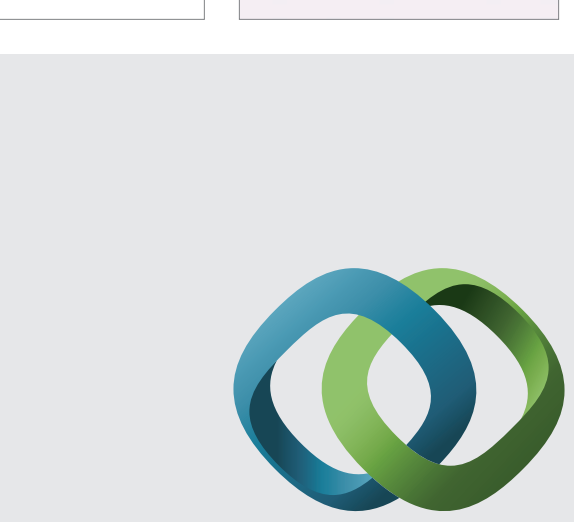

\section{Hindawi}

Submit your manuscripts at

http://www.hindawi.com
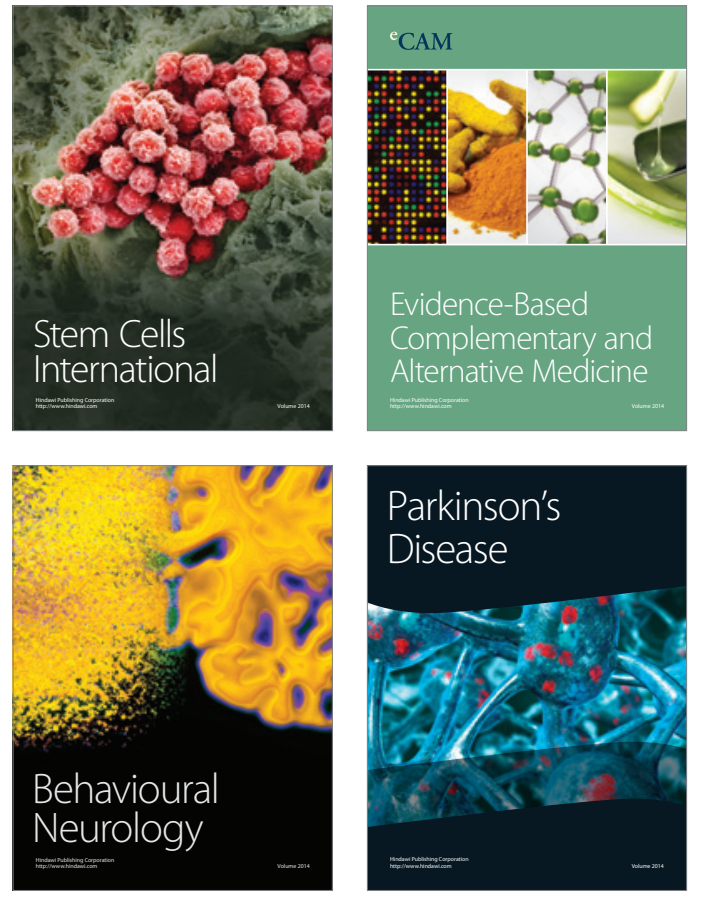
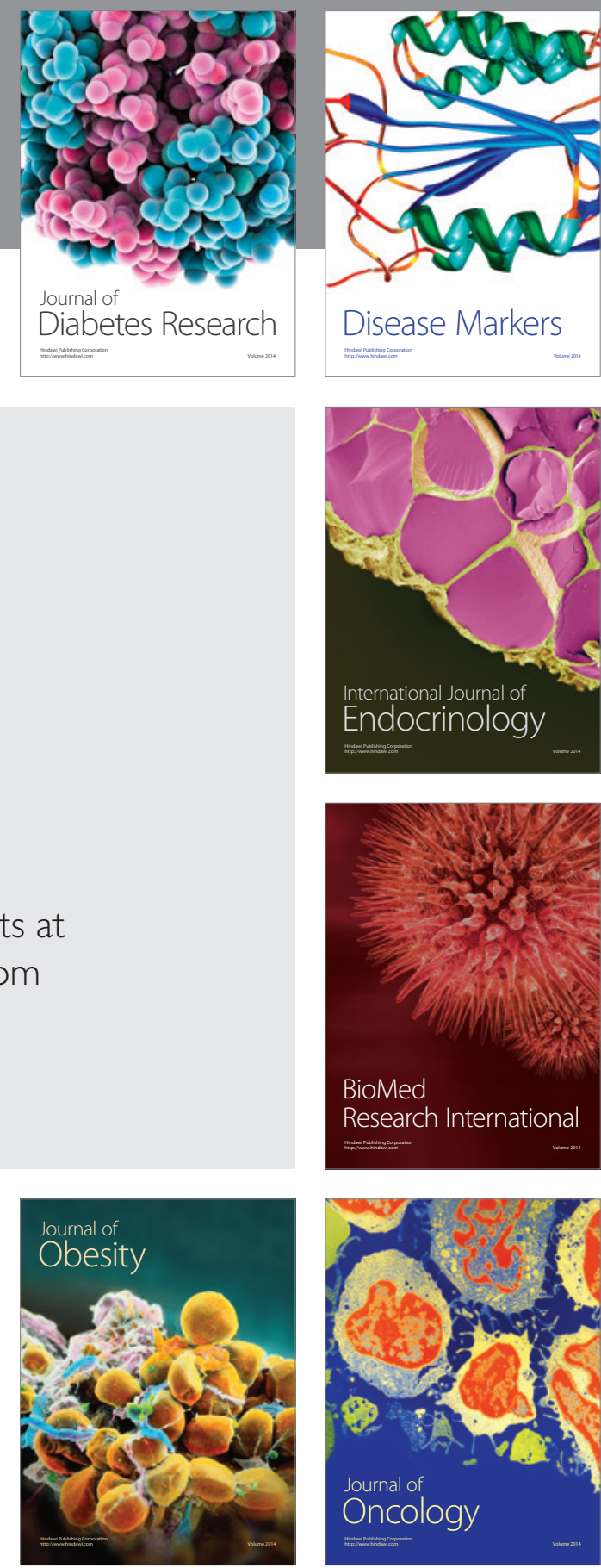

Disease Markers
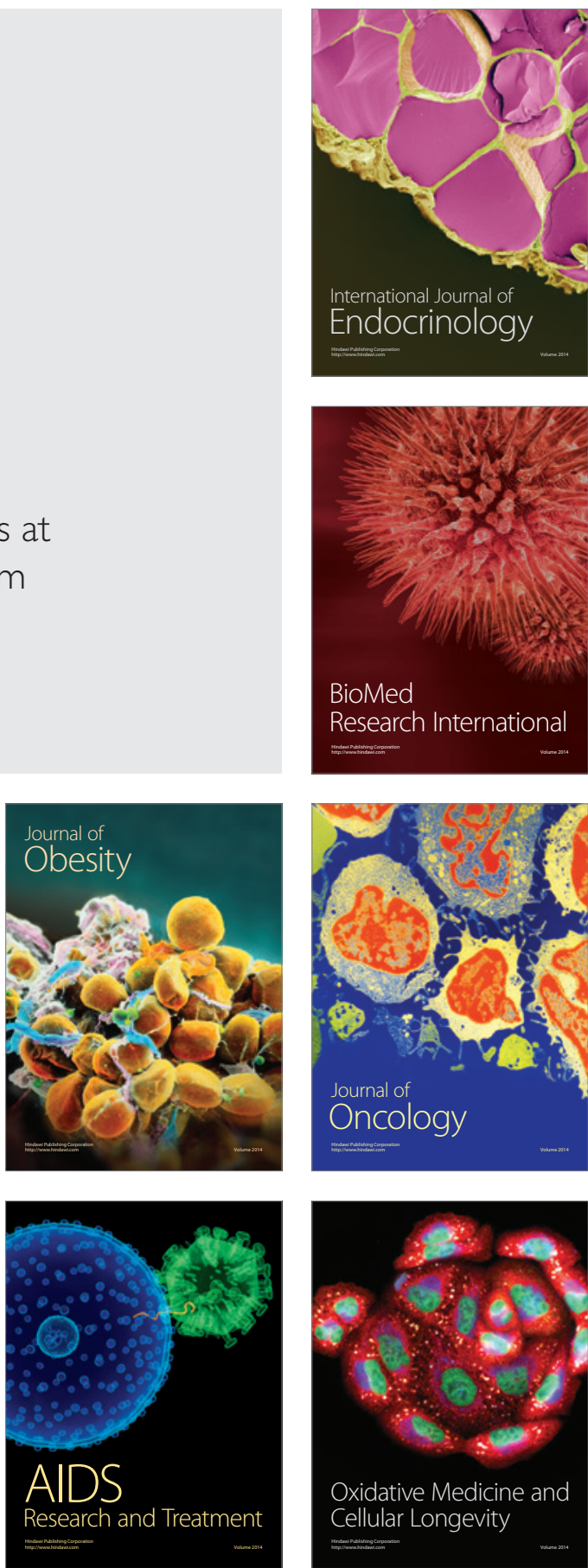